\title{
Low-cost Temperature Transition Mixtures (TTM) based on ethylene glycol/potassium hydroxide as reversible $\mathrm{CO}_{2}$ sorbents
}

\author{
Marcello Costamagna, ${ }^{a}$ Eleonora Micheli, ${ }^{a}$ Valentino Canale ${ }^{\mathrm{b}}$, Michele Ciulla ${ }^{\mathrm{b}}$, Gabriella Siani ${ }^{\mathrm{b}}$, Pietro \\ di Profio ${ }^{\mathrm{b}}$, Matteo Tiecco, ${ }^{\mathrm{c}^{*}}$ Gianluca Ciancaleoni ${ }^{\mathrm{a}, \mathrm{d} *}$
}

a. Dipartimento di Chimica e Chimica Industriale (DCCI), Università di Pisa, Via Giuseppe Moruzzi, 13 -56124 Pisa, Italy

b. Dipartimento di Farmacia, Università Gabriele d'Annunzio, Via dei Vestini 31, 66100 Chieti, Italy

c. Dipartimento di Chimica, Biologia e Biotecnologie, Università di Perugia, via Elce di Sotto 8, I-06123 Perugia, Italy

d. CIRCC, Via Celso Ulpiani 27, I-70126 Bari, Italy

* Corresponding author

Email address: matteotiecco@gmail.com; gianluca.ciancaleoni@unipi.it

\begin{abstract}
A low-cost Transition Temperature Mixture (TTM) has been synthesized by mixing ethylene glycol and potassium hydroxide as a new non-aqueous $\mathrm{CO}_{2}$ sorbent. Boric acid has been added to ensure the reversibility of the system and a small amount of water to modulate the viscosity and optimize the performances. The resulting mixtures have been characterized in terms of viscosity, conductivity and density over temperature (therefore ionicity via Walden plots) and the effect of temperature, pressure and the kinetics of the absorption have been evaluated. Under optimized conditions, the four-component mixture EG/KOH/BA/ $/ \mathrm{H}_{2} \mathrm{O} 3: 1: 1: 3$ can absorb $24 \mathrm{~g}_{\mathrm{CO} 2} / \mathrm{kg}_{\text {sorbent }}$ in 30 minutes at $35^{\circ} \mathrm{C}$ at 1 atm $(59$ after $4 \mathrm{~h}$ ) and $60 \mathrm{~g}_{\mathrm{CO} 2} / \mathrm{kg}_{\text {sorbent }}$ in 30 minutes at high pressure (10 and $20 \mathrm{~atm}, 80 \mathrm{~g}_{\mathrm{CO} 2} / \mathrm{kg}_{\text {sorbent }}$ after $50 \mathrm{~min}$ ), while the desorption is quantitative after 30 minutes at only $60^{\circ} \mathrm{C}$ under a gentle $\mathrm{N}_{2}$ flow. The system is robust enough to ensure multiple absorption/desorption cycles.
\end{abstract}

\section{KEYWORDS}

Transition Temperature Mixtures

Structured liquids

$\mathrm{CO}_{2}$ absorption 


\section{Carbon Capture}

High pressure experiments

\section{INTRODUCTION}

The official European energy strategy for a climate-neutral future states that electricity from renewable sources will be the primary source of energy for all the needs of the society.[1] For the applications that requires a high density fuel, as heavy industry or air transportation, water electrolyzers will produce green hydrogen as fuel.[2,3] This strategy will allow the reduction of the $\mathrm{CO}_{2}$ emission and avoid the depletion of fossil fuels, preserving them and the environment for future generations. Unfortunately, the transition will necessarily last several years, and temporary solutions are required during the transition from the current energy market to the next one.

In particular, as stated in the same document, no realistic goal is achievable in the near term without the use of carbon capture (CC) methods, in order to remove $\mathrm{CO}_{2}$ from the industrial flue gases and use it for the synthesis of high-added value chemicals (Carbon Capture and Utilization, CCU) or store it into accurately chosen sites (Carbon Capture and Storage CCS).[4-7] It must be said that all the long-term strategies has still serious drawbacks and, in many cases, considering the entire cycle (including transportation of the absorbed $\mathrm{CO}_{2}$ and its regeneration, among the other factors), current CCUS strategies sequester less $\mathrm{CO}_{2}$ than that they emit it.[8] Anyway, this does not mean that we do not need CCUS strategies, but only that we need better strategies than the existing ones, with optimal capacity, selectivity, recyclability, stability and cost.[9]

Generally speaking, the most mature CC technologies take advantage of two chemical reactions, by using aqueous monoethanolamine (MEA) solutions or aqueous alkaline hydroxides and carbonates as sorbents (Scheme 1).

Indeed, MEA is cheap, has a good kinetic of absorption and carbamate production and, if heated $(\sim 130$ ${ }^{\circ} \mathrm{C}$ ), gives back the $\mathrm{CO}_{2}$, restoring the sorbent.[10] Unfortunately, even if the boiling point of MEA is high, a small amount of amine evaporates or undergoes degradation into environmentally unfriendly products (as nitrosamines and nitramines[11,12]) at every cycle. Moreover, reaching $130^{\circ}$ requires an high amount of energy, since water has a high thermal capacity, $\mathrm{C}_{\mathrm{H} 2 \mathrm{O}}=1 \mathrm{cal} /\left({ }^{\circ} \mathrm{C} \mathrm{g}\right)$ at $25{ }^{\circ} \mathrm{C}$, and most of the energy used to raise the temperature of the system is absorbed by water and not by the actual sorbent system. Many strategies to make the regeneration milder are under study, and using non-aqueous solvents is the most promising one.[13-15] 
a)

$2 \mathrm{HO} \mathrm{NH}_{2}+\mathrm{CO}_{2} \underset{130^{\circ} \mathrm{C}}{\rightleftharpoons} \mathrm{HO}^{\sim} \mathrm{NH}_{3}{ }^{+} \mathrm{HO} \frown \mathrm{NHCOO}^{-}+$decomp.

b)

$\mathrm{KOH}_{(\mathrm{aq})}+\mathrm{CO}_{2} \longrightarrow \mathrm{KHCO}_{3(\mathrm{aq})}$

$\mathrm{KHCO}_{3(\mathrm{aq})}+\mathrm{Ca}(\mathrm{OH})_{2(\mathrm{aq})} \longrightarrow \mathrm{CaCO}_{3(\mathrm{~s})}+\mathrm{KOH}_{(\mathrm{aq})}+\mathrm{H}_{2} \mathrm{O}_{(\mathrm{l})}$

$\mathrm{CaCO}_{3(\mathrm{~s})} \stackrel{>700^{\circ} \mathrm{C}}{\longrightarrow} \mathrm{CaO}_{(\mathrm{s})}+\mathrm{CO}_{2(\mathrm{~g})}$

$\mathrm{CaO}_{(\mathrm{s})}+\mathrm{H}_{2} \mathrm{O}_{(\mathrm{l})} \longrightarrow \mathrm{Ca}(\mathrm{OH})_{2(\mathrm{aq})}$

c)

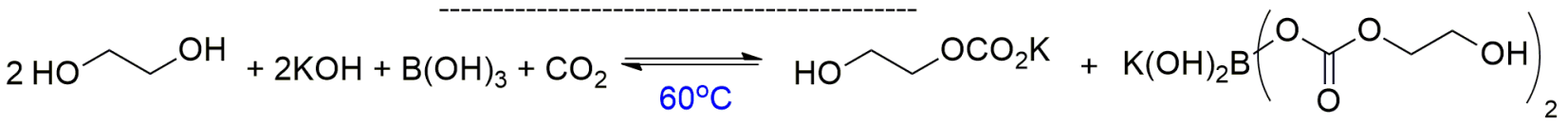

Scheme 1. Chemical reactions involved in the carbon capture strategies for a) MEA, b) $\mathrm{KOH} / \mathrm{CaO}$ and c) $\mathrm{EG} / \mathrm{KOH} / \mathrm{B}(\mathrm{OH})_{3}$ (this work).

Also alkaline hydroxides/carbonates are cheap, possess good absorption capacity and are more stable than amines to degradation. The drawback is that the product, alkaline bicarbonates, are thermally stable and they need to be converted in $\mathrm{CaCO}_{3}$, which gives back the $\mathrm{CO}_{2}$ during the calcination step at a temperature higher than $700^{\circ} \mathrm{C}$.[16-18] Obviously, this step is a huge $\mathrm{CO}_{2}$ emitter that should be avoided. Alternative systems are currently under study, as Metal Organic Frameworks,[19] for which a simple pressure swing cycle is enough to adsorb and desorb $\mathrm{CO}_{2}$. Generally, they are not as cheap as MEA and $\mathrm{KOH}$, but there are some notable exceptions on the way for industrial applications.[20]

Recently, ionic liquids (ILs) and Deep Eutectic Solvents (DESs) have been extensively studied as $\mathrm{CO}_{2}$ sorbents.[21,22] Some of them are physical sorbents and they take advantage of the Henry's law to absorb/desorb $\mathrm{CO}_{2}$. In these cases, the absorption step must be conducted at high pressure and the desorption is easier, even at ambient pressure and temperature. In other cases, the absorption depends on a chemical reaction, as they contain one or more amine groups, but also alternative reactions have been explored.[23] The main drawbacks of ILs are their high price and their high environmental impact that hamper the large-scale applications, whereas DESs are scalable, cheap and, in many cases, biodegradable.

In some cases, ethylene glycol (EG) and other glycols has been considered as a suitable component for $\mathrm{CO}_{2}$ sorbent systems.[13,24,25] The choice is particularly wise because the thermal capacity if EG is about one half that of water $\left(\mathrm{C}_{\mathrm{EG}}=0.58 \mathrm{cal} /\left({ }^{\circ} \mathrm{C} \mathrm{g}\right)\right.$ at $\left.25^{\circ} \mathrm{C}\right)$, making the heating less energy-requiring. It is quite viscous $\left(\mu_{\mathrm{EG}}=16.1 \mathrm{cP}\right.$ at $\left.25^{\circ} \mathrm{C}\right)$ and it is already globally employed,[26] with an industrial production of 20 million metric tons in 2010. Indeed, it is used in many products and processes: as 
coolant, solvent and precursor of polyesters, among others. Notably, EG can be derived from biomass and, under this point of view, considered renewable.[27] Unfortunately, most of the current production passes through the oxidation of ethylene, which is not renewable.

In this paper, we explored the potential of liquid systems based on inexpensive, abundant and safe materials, as EG and $\mathrm{KOH}$ in $\mathrm{CC}$ strategies, with the addition of boric acid $\left(\mathrm{H}_{3} \mathrm{BO}_{3}, \mathrm{BA}\right)$ to ensure reversibility (Scheme 1).

The systems have been characterized in terms of viscosity, conductivity and density, in order to characterize their ionicity through the Walden plot. Then, their absorption/desorption capacities have been tested and, interestingly, they showed no substantial increase of viscosity upon $\mathrm{CO}_{2}$ absorption. The results show that under optimized conditions, the $\mathrm{CO}_{2}$ absorption is between 17 and $80 \mathrm{~g}_{\mathrm{CO} 2} / \mathrm{kg}_{\mathrm{sorbent}}$, depending on the time of contact, pressure, amount of water and temperature, while the desorption is complete after 30 minutes at $60^{\circ} \mathrm{C}$ and under a gentle nitrogen flow. The system is stable enough to allow multiple cycles without any significant loss of performance.

\section{RESULTS AND DISCUSSION}

Preparation and characterization of systems. EG/KOH. For the preparation of an effective sorbent, it is important to use the minimal amount of the solvent, in order to maximize the ratio between the amount of absorbed $\mathrm{CO}_{2}$ and the mass of the sorbent, but also to reduce the cost of the material. For this reason, we started mixing $\mathrm{EG}$ and $\mathrm{KOH}$ in equimolar amounts. It was known that $\mathrm{KOH}$ is soluble in EG, but we were surprised to see that the 1:1 mixture is already a homogenous, viscous liquid. Evidently, the system is not a simple "solution", but $\mathrm{KOH}$ enters directly in the structure of the liquid. For example, the potassium can interact with one or more molecules of EG, giving an adduct that presumably reduces the electrostatic interaction with the hydroxide and, consequently, its reticular energy. Furthermore, the chemical equilibrium

$$
\mathrm{KOH}+\mathrm{HOCH}_{2} \mathrm{CH}_{2} \mathrm{OH} \leftrightarrows \mathrm{K}^{+} \mathrm{HOCH}_{2} \mathrm{CH}_{2} \mathrm{O}^{-}+\mathrm{H}_{2} \mathrm{O}
$$

produces some water, favouring the formation of a liquid. Notably, ${ }^{13} \mathrm{C}$ NMR spectra of pure EG and EG/KOH are very similar to each other (see Experimental Section and Figures S1 and S3 for details), making us to think that the equilibrium is fast (otherwise two sets of signals would have been present) and shifted to the left. 
This system has to be prepared under inert atmosphere (nitrogen or argon) to avoid a base-promoted oxidation of the EG, which leads the system to be pale yellow when exposed to air and, if heated, dark yellow.

Anyway, the high viscosity of the liquid makes the system impracticable for $\mathrm{CO}_{2}$ absorption, as the gas penetration in the liquid is largely hampered. Increasing the amount of EG up to EG/KOH 3:1 induces a sensible lowering of the viscosity (system A). Also in this case, the ${ }^{13} \mathrm{C} N \mathrm{NM}$ spectrum remains practically unchanged. Any attempt to evaluate the exact amount of water and characterize the equilibrium (1) was unsuccessful: for instance, the Karl Fischer titration failed due to the extremely basic nature of the liquid.

The viscosity $\eta$ of $\mathbf{A}$ goes from $330 \mathrm{cP}$ at $25^{\circ} \mathrm{C}$ to $33 \mathrm{cP}$ at $70^{\circ} \mathrm{C}$, lower than many DES and ILs, while the exponential trend indicates that it behaves as a Newtonian liquid. On the other hand, the conductivity $\sigma$ goes from $4.03 \mathrm{mS} / \mathrm{cm}$ at room temperature to $16.27 \mathrm{mS} / \mathrm{cm}$ at $70^{\circ} \mathrm{C}$, also in this case following an exponential trend (Figure S14-16, Supplementary Information). The observed conductivity values are higher than typical values of DESs, supporting the presence of ionic species with a good mobility.[28,29] Plotting the logarithm of both viscosity and conductivity against the inverse of the temperature (Figure 1), the corresponding activation energies, $E_{\eta}$ and $E_{\sigma}$ respectively, can be estimated. They result to be $E_{\eta}$ $=0.62$ and $E_{\sigma}=0.38 \mathrm{~kJ} / \mathrm{mol}$. The value of $E_{\eta}$ is quite small if compared with the ones of other solvents or other similar liquids.[30-32] This means an easy capability in the liquid structure to form vacancies, which could represent an advantage in $\mathrm{CO}_{2}$ capture process. Also the value of $\mathrm{E}_{\sigma}$ is quite small compared to other fluids,[28] and this is related to an easy diffusion of charged species in the fluids. The good adherence of experimental data of $\sigma$ and $\eta v s$. temperature with an exponential trend allows the use of the Walden rule as a qualitative tool to obtain structural information on our system.

Indeed, according to the Walden rule, the product of the molar conductivity $\Lambda$ and the fluidity $\left(\eta^{-1}\right)$ is a constant. Equation (2) is the logarithmic form of the Walden rule,

$$
\ln \Lambda=\ln k+\ln \eta^{-1}
$$

where $k$ is a temperature-dependent constant. Notably, many ILs, transition temperature mixtures (TTMs) and DESs fall below the reference line (an aqueous solution of $\mathrm{KCl} 0.01 \mathrm{M}$ ),[32-35] and are labelled as "true" or "poor" ionic liquids, whereas molten inorganic salts generally fall well above the reference ("super" ionic liquid).[36]

In our case, the Walden plot reveals that the $\mathbf{A}$ mixture falls slightly above the reference, in the region of "good ionic liquids", with a good ionic mobility. 

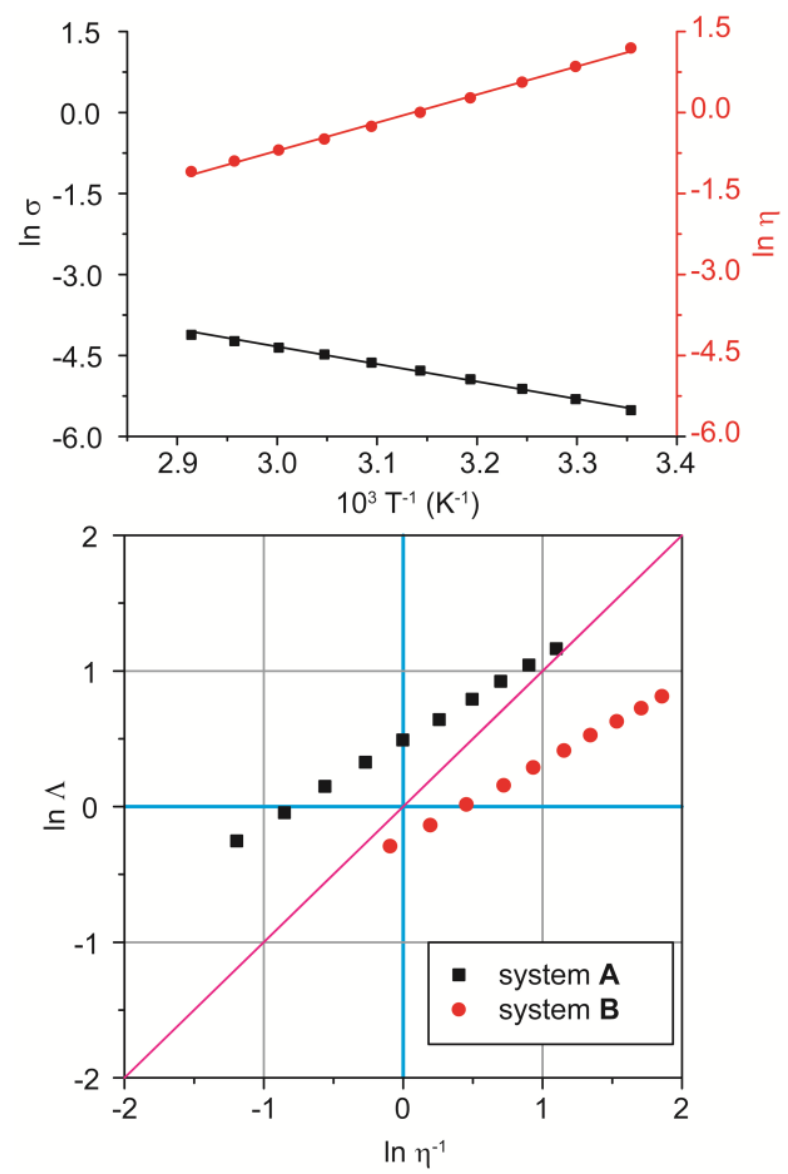

Figure 1. (a) Viscosity (red) and conductivity (black) for the mixture EG/KOH 3:1; (b) Walden plot for system $\mathbf{A}$ and $\mathbf{B}$. The purple line represents the plot for a diluted aqueous solution of $\mathrm{KCl}$.

Lowering the temperature, a glass transition to an amorphous solid has been measured between -34 and $-40^{\circ} \mathrm{C}$ with a plastic-like behaviour between the two values. Considering that $\mathrm{EG}$ and $\mathrm{KOH}$ have a m.p. of -13 and $360^{\circ} \mathrm{C}$, respectively, system A can be considered a TTM, similarly to the chemically analogue potassium carbonate/glycol reported in literature.[37]

When exposed to a $\mathrm{CO}_{2}$ atmosphere at room temperature, the system increases its weight of about $14 \%$ and becomes cloudy. This indicates the absorption of 0.9 mol $\mathrm{CO} 2 / \mathrm{mol}_{\mathrm{KOH}}\left(140 \mathrm{~g}_{\mathrm{CO} 2} / \mathrm{kg}_{\mathrm{sorbent}}\right)$ and the formation of potassium bicarbonate, which is poorly soluble in this mixture. Actually, the ${ }^{13} \mathrm{C}$ NMR spectrum of the resulting mixture indicates that the carbonation of the system leads to two products (Figure 2): not only potassium bicarbonate (carbon peak around $167 \mathrm{ppm}$ ), as confirmed from the reference spectrum of $\mathrm{KHCO}_{3}$ in pure EG (Figure S2, Supplementary Information), but also another species with three different carbon nuclei. This species is the carbonate of ethylene glycol[38,39] derived 
from the deprotonation of EG by the hydroxide. The low relative abundance of the latter with respect to the peak of EG is an additional, indirect confirmation that the equilibrium (1) is shifted to the left.

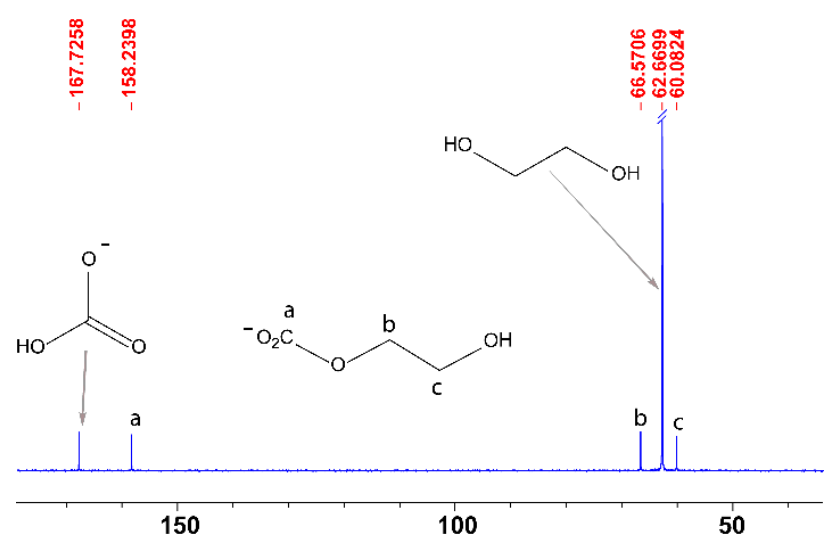

Figure 2. ${ }^{13} \mathrm{C}\left\{{ }^{1} \mathrm{H}\right\}$ spectrum of $\mathrm{EG} / \mathrm{KOH}(3: 1)+\mathrm{CO}_{2}$ (external lock).

As expected, the heating of the carbonated system did not lead to the decomposition of the bicarbonate back to $\mathrm{KOH}$ and $\mathrm{CO}_{2}$, even in the presence of a reduced pressure $(0.1 \mathrm{~atm})$. On the contrary, the prolonged heating makes the yellowing of the liquid faster. The addition of any acid, as sulfuric or oxalic acid, leads to the immediate and quantitative release of $\mathrm{CO}_{2}$ and precipitation of the corresponding salt, but in this case only the EG could be recycled and new $\mathrm{KOH}$ should be added after every cycle, increasing the amount of by-products (even if not toxic) and making the system less sustainable. Anyway, more elaborated $\mathrm{pH}$ swing strategies could be tested in the future.[40]

EG/KOH/BA. During the $\mathrm{CO}_{2}$-release test by acidification, we noted that if boric acid (BA) was used, there was no precipitation of the corresponding salt, namely potassium tetrahydroxyborate, during the effervescence and the resulting solution appeared not only homogeneous, but also less viscous than the initial EG/KOH 3:1 mixture. Therefore, we decided to incorporate BA before the carbonation. Indeed, boron species has already been recognized as a catalyst for bicarbonate decomposition or $\mathrm{CO}_{2}$ sorbents.[41-45]

The mixture EG/KOH/BA 3:1:1 (system B) is a clear and not very viscous liquid. The ${ }^{13} \mathrm{C}$ NMR spectrum shows that also in this case the peak of EG is practically unaltered (Figure S5). In addition, the ${ }^{11} \mathrm{~B}$ NMR spectrum shows two broad peaks (Figure S6). BA is known to have a complex speciation in water depending on the $\mathrm{pH}$ of the solution.[46] Less is known about the speciation in EG, but on the ground of the nature of system $\mathbf{B}$ and what said before, we can safely hypothesize that the two peaks are relative to 
$\mathrm{KB}(\mathrm{OH})_{4}$ and the Lewis adduct between $\mathrm{BA}$ and the potassium salt of $\mathrm{EG}, \mathrm{KB}(\mathrm{OH})_{3}\left(\mathrm{OCH}_{2} \mathrm{CH}_{2} \mathrm{OH}\right)$. This is partially confirmed by the elemental analysis: if system $\mathbf{B}$ is heated for 6 hours under reduced pressure, a white solid remains, the elemental analysis of which is coherent with a 1:1 mixture of $\mathrm{KB}(\mathrm{OH})\left(\mathrm{OCH}_{2} \mathrm{CH}_{2} \mathrm{OH}\right)_{3}$ and $\mathrm{KOCH}_{2} \mathrm{CH}_{2} \mathrm{OH}$ (see Experimental Details). The extensive substitution on the boron is likely a consequence of prolonged dehydration of the system, anyway at room temperature and under basic conditions, the substitution of at least one hydroxide appears likely. In addition, the presence of two broad peaks induces to think that the two species are in slow equilibrium with each other.

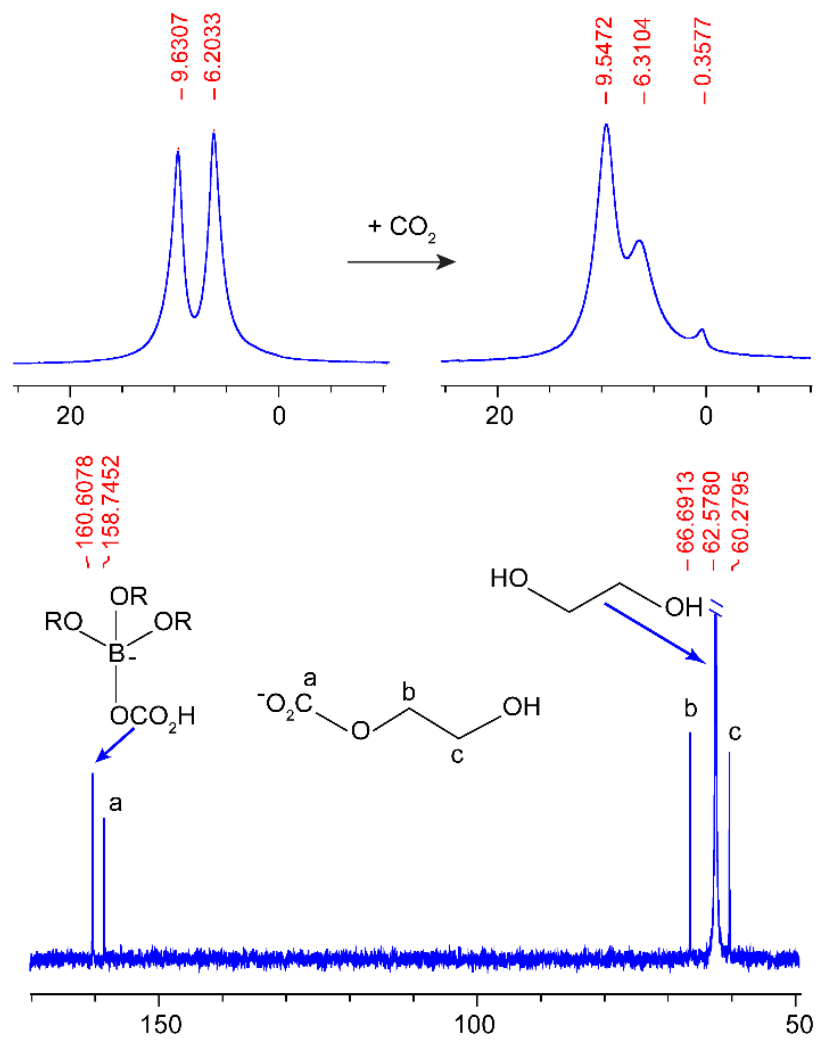

Figure 3. (up) ${ }^{11} \mathrm{~B}$ NMR spectrum of the mixture EG/KOH/BA 3:1:1 before and after carbonatation. (down) ${ }^{13} \mathrm{C}\left\{{ }^{1} \mathrm{H}\right\}$ spectrum of EG/KOH/BA $(3: 1: 1)+\mathrm{CO}_{2}$ (external lock). $\mathrm{R}=\mathrm{H}$ or $\mathrm{OCH}_{2} \mathrm{CH}_{2} \mathrm{OH}$.

Moreover, BA protects also the system from the base-promoted oxidation, and the EG/KOH/BA 3:1:1 mixture can be stored without inert atmosphere without any degradation for several weeks.

The trends of $\mu$ and $\eta$ with T for system B are shown in Figure 4 (Figure S17-19). Also in this case, they are clearly exponential, with activation barriers of 0.53 and $0.30 \mathrm{~kJ} / \mathrm{mol}$ for the viscosity and conductivity, respectively. These values are lower than in the absence of BA and again lower than the values observed for other similar liquids or solvents as for system A.[30-32] The Walden plot indicates 
that this system lies under the bisector, indicating a poor-ionic liquid (Figure 1), with a higher degree of association between the ions. As the viscosity is lower, the lower mobility of ions can be explained by the larger size of substituted borate species. The glass transition temperature of the system $\mathbf{B}$ is between -53 and $-46{ }^{\circ} \mathrm{C}$, lower than in the absence of BA. Also in this case, the physical properties of system B clearly indicate the nature of this liquid as a TTM.

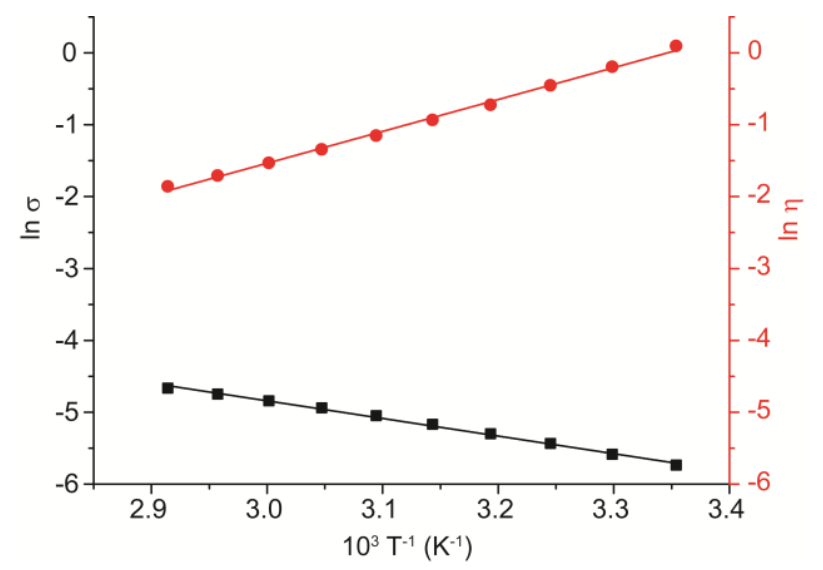

Figure 4. Viscosity (red) and conductivity (black) for the mixture EG/KOH/BA 3:1:1. Straight lines represent the best fit lines.

This system, when exposed to an atmosphere of pure $\mathrm{CO}_{2}$, increases its weight of about $2 \%$, which indicates the absorption of $12 \% \mathrm{~mol}_{\mathrm{CO} 2} / \mathrm{mol}_{\mathrm{KOH}}$ at $20^{\circ} \mathrm{C}\left(17 \mathrm{~g}_{\mathrm{CO} 2} / \mathrm{kg}_{\text {sorbent }}\right)$. This is much lower than system $\mathbf{A}$, but in this case no precipitation is observed. The $\mathrm{pH}$ of the system falls down from 10.80 to 9.66 (Figure S24), providing a good semi-quantitative method to follow the absorption process. The ${ }^{13} \mathrm{C}$ NMR spectrum shows that the carbonate of the ethylene glycol is still present, again with a peak that is much smaller than that of EG (Figure 3). The second peak at $160.3 \mathrm{ppm}$ is not relative to $\mathrm{KHCO}_{3}$, which would be at $167 \mathrm{ppm}$ as seen before, but it is likely the Lewis adduct between $\mathrm{B}(\mathrm{OR})_{3}$ and $\mathrm{RCO}_{3}{ }^{-}(\mathrm{R}=-$ $\mathrm{H}$ or $-\mathrm{CH}_{2} \mathrm{CH}_{2} \mathrm{OH}$, Figure 3). In the ${ }^{11} \mathrm{~B}$ NMR spectrum, a third species arose at $0.35 \mathrm{ppm}$ and the species at $6.3 \mathrm{ppm}$ was greatly reduced in intensity. The position of the new peak is compatible with the $(\mathrm{OR})_{3} \mathrm{~B}\left(\mathrm{RCO}_{3}\right)^{-}$species.

If kept for several hours at rest, a white precipitate finally appears, revealing the metastable nature of the solution. When filtered and dried, the elemental analysis of the solid is coherent with a formulation $\mathrm{KB}(\mathrm{OH})_{2}\left(\mathrm{O}_{2} \mathrm{COCH}_{2} \mathrm{CH}_{2} \mathrm{OH}\right)_{2}$. When redissolved in deuterated water, the ${ }^{11} \mathrm{~B} \mathrm{NMR}$ spectrum shows a single peak at $9.3 \mathrm{ppm}$, whereas the ${ }^{13} \mathrm{C}$ NMR spectrum shows the signal of EG, and a signal in the region of bicarbonate in water (162.2 ppm). Likely, water hydrolyses the borate anion, giving again the ethylene 
glycol and giving bicarbonate anions, which interact with boric acid. This has been confirmed mixing $\mathrm{B}(\mathrm{OH})_{3}$ and $\mathrm{KHCO}_{3} 1: 1$ in deuterated water, which gives the same ${ }^{11} \mathrm{~B}$ NMR signal and a similar peak in the ${ }^{13} \mathrm{C}$ NMR spectrum (160.4 ppm).

The thermal gravimetric analysis (TGA) of the carbonated system $\mathbf{B}$ reveals a loss of mass at $56^{\circ} \mathrm{C}$, and another one that starts at $150^{\circ} \mathrm{C}$ (Figure S13). On the basis of this information, we heated at $60^{\circ} \mathrm{C}$ under a reduced pressure $(0.1 \mathrm{~atm})$ or under a gentle nitrogen flow the carbonated system $\mathbf{B}$ for 30 minutes and, to our delight, in both cases all the peaks in the ${ }^{13} \mathrm{C}$ NMR spectrum relative to carbonate species completely disappeared, leaving only the peak of EG (Figure 5). A careful evaluation of the spectrum reveals that barely detectable traces of carbonated species are still present, slightly over the detection limit of the instrument. Evidently, the boric acid acts as a mediator for the decomposition of bicarbonates, as also stated in literature for aqueous solutions. [42,44] Coherently, the $\mathrm{pH}$ of the system increases upon regeneration, indication that the system has been fully restored to the initial conditions. But the loss of weight is larger than the weight gained in the absorption step, meaning that $\mathrm{CO}_{2}$ is not the only volatile. In fact, also water is lost and analysing the TGA of $\mathrm{CO}_{2}$-free systems $\mathbf{A}$ and $\mathbf{B}$ (Figure S10-11), it results that dehydration happens approximately at the same temperature than $\mathrm{CO}_{2}$. For this reason, the system needs to be rehydrated after desorption.

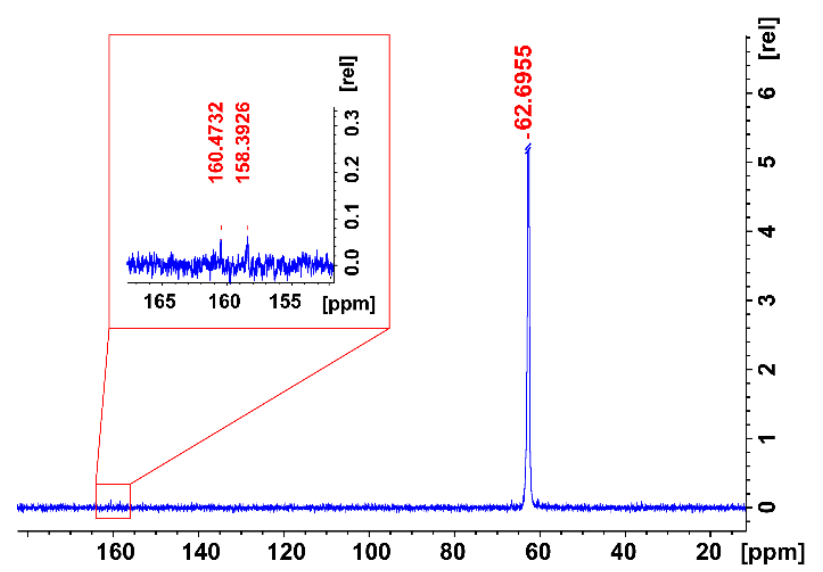

Figure 5. ${ }^{13} \mathrm{C}\left\{{ }^{1} \mathrm{H}\right\}$ spectrum of system $\mathbf{B}(\mathrm{EG} / \mathrm{KOH} / \mathrm{BA} 3: 1: 1)+\mathrm{CO}_{2}$ (external lock) after a thermal treatment $\left(60^{\circ} \mathrm{C}\right.$ for 30 min under a gentle $\mathrm{N}_{2}$ flow).

The viscosity, the conductivity and the density values have been measured also for the carbonated system and they resulted to be very close to the non-carbonated system (Table S1), giving a superimposable Walden plot. The almost identical viscosities before and after $\mathrm{CO}_{2}$ absorption is important as many non- 
aqueous sorbent systems increase their viscosity upon carbonation, which can be problematic in large scale applications.

The absorbed $\mathrm{CO}_{2}$ has been gravimetrically measured after different times, reaching 17 and 59 $\mathrm{g}_{\mathrm{CO} 2} / \mathrm{kg}_{\text {sorbent }}$ after 0.5 and 4 hours, respectively (initial rate $0.8 \mathrm{~g}_{\mathrm{CO} 2} / \mathrm{kg}_{\text {sorbent }} *$ min, Figure $\mathrm{S} 23$ ). The thickness of the layer and the stirring rate are obviously crucial for the absorption kinetics, which likely can be further optimized by a wise choice of the experimental setup, for instance using the liquid sorbent in the form of aerosol or thin layers to maximize the surface of contact with the gas.

As MEA is considered a benchmark for $\mathrm{CO}_{2}$ absorption, a comparison under similar conditions can be

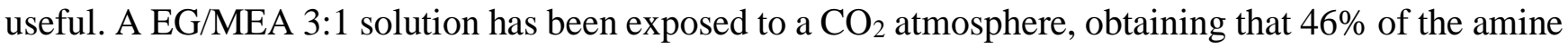
has been carbonated ( $\left.82 \mathrm{~g}_{\mathrm{CO} 2} / \mathrm{kg}_{\mathrm{s} o r b e n t}\right)$, generating the ammonium carbamate. A small amount of the glycol carbonate is obtained, too (Supporting Information), which derives from the deprotonation of EG by MEA. Unfortunately, both TGA and NMR confirms that the thermal treatment used for system B $\left(60^{\circ} \mathrm{C}\right.$ for $30 \mathrm{~min}$ under a gentle $\mathrm{N}_{2}$ flow) is not enough to decompose back the carbamate into MEA and $\mathrm{CO}_{2}$. Indeed, carbonated MEA is generally regenerated at higher temperatures (Scheme 1). In brief, our system absorbs less carbon dioxide, but allows milder conditions for the regeneration. In addition, no potentially dangerous volatiles are emitted in this step (just $\mathrm{CO}_{2}$, water and traces of EG), whereas the amine that evaporates during the regeneration step can decompose to toxic by-products.

Optimization and recycle of system $\mathbf{B}$. The relatively low $\mathrm{CO}_{2}$ absorption of system $\mathbf{B}$ is certainly due to its less basic nature with respect to system $\mathbf{A}$, as it contains an acid.

For this, a mixture containing only 0.25 equivalents of BA has been prepared and the absorption capacity increased back to $76 \mathrm{~g}_{\mathrm{CO} 2} / \mathrm{kg}_{\text {sorbent }}$. Unfortunately, as in the case of system $\mathbf{A}$, the mixture resulted to become yellow with time, even if more slowly than system A, and the formation of bicarbonate ions, as in Figure 2, made the regeneration impossible. Therefore, the presence of less than 1 equivalent of BA is not able to solve the two main drawback of system $\mathbf{A}$, degradation and irreversibility.

The other factor hampering the absorption capacity is the viscosity. Even if less viscous than system $\mathbf{A}$, this aspect of system $\mathbf{B}$ can be still optimized. Therefore, we repeated the $\mathrm{CO}_{2}$ absorption step at different temperatures with system $\mathbf{B}$, obtaining the maximum of absorption at around $35^{\circ} \mathrm{C}\left(25 \%\right.$ mol $\mathrm{CO} 2 / \mathrm{mol}_{\mathrm{KOH}}$, $37 \mathrm{~g}_{\mathrm{CO} 2} / \mathrm{kg}_{\text {sorbent }}$ ). After this value, the system absorbs less $\mathrm{CO}_{2}$, probably because the temperature approaches that of the desorption step (Figure 6). 


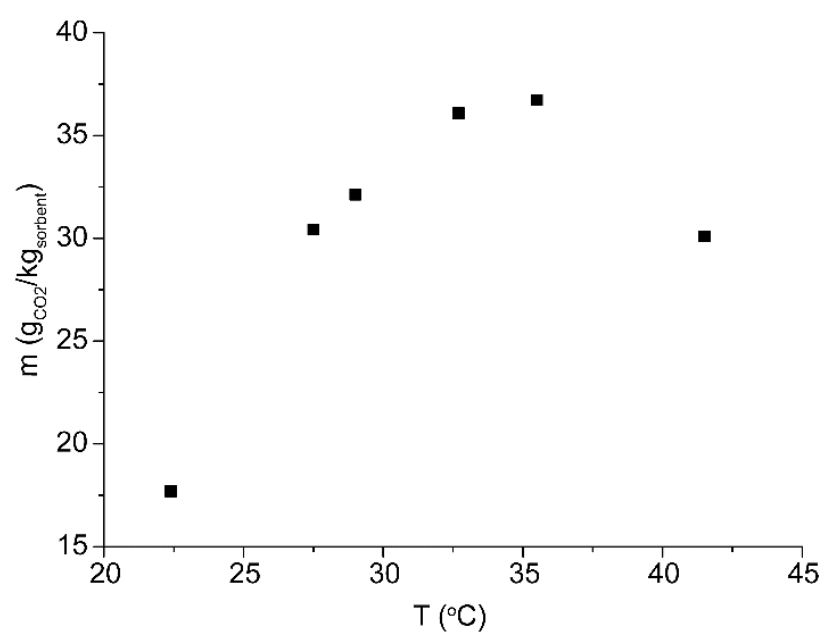

Figure 6. Absorption trend with temperature of system $\mathbf{B}$.

In a further attempt to reduce the viscosity, the absorption step has been conducted with 2 (system $\mathbf{C}$, $\mathrm{EG} / \mathrm{KOH} / \mathrm{BA} / \mathrm{H}_{2} \mathrm{O}=3: 1: 1: 2$ ) and 3 equivalents of water (system $\mathbf{D}, \mathrm{EG} / \mathrm{KOH} / \mathrm{BA} / \mathrm{H}_{2} \mathrm{O}=3: 1: 1: 3$ ). As implied in the equilibrium (1), water is already present in the mixture, although in a small amount, and needs anyway to be added after every desorption step. For this, adding some equivalents does not alter the nature of the system and, given its low molecular weight, does not increase much the average thermal capacity of the mixture. In the presence of water and consequently with a lower viscosity, the $\mathrm{CO}_{2}$ absorption performances get better, reaching 23 and $30 \mathrm{~g} \mathrm{gO}_{2} / \mathrm{kg}_{\text {sorbent }}$ at room temperature for system $\mathbf{C}$ and $\mathbf{D}$, respectively.

Finally, the recyclability and robustness of system $\mathbf{B}$ have been tested, performing 10 consecutive absorption/desorption cycles. At each cycle, $\mathrm{CO}_{2}$ has been absorbed at the temperature of $28^{\circ} \mathrm{C}$ for 30 minutes and desorbed at $60^{\circ} \mathrm{C}$ (together with water) for other 30 minutes. At the end of each cycle, the system has been rehydrated, restoring the weight of the original system (Figure 7). The average capacity

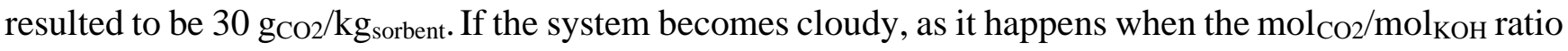
exceeds $20 \%$, it can be regenerated without redissolving the precipitate. Anyway, some drops of water can be added to restore the homogeneity of the liquid, if needed. 


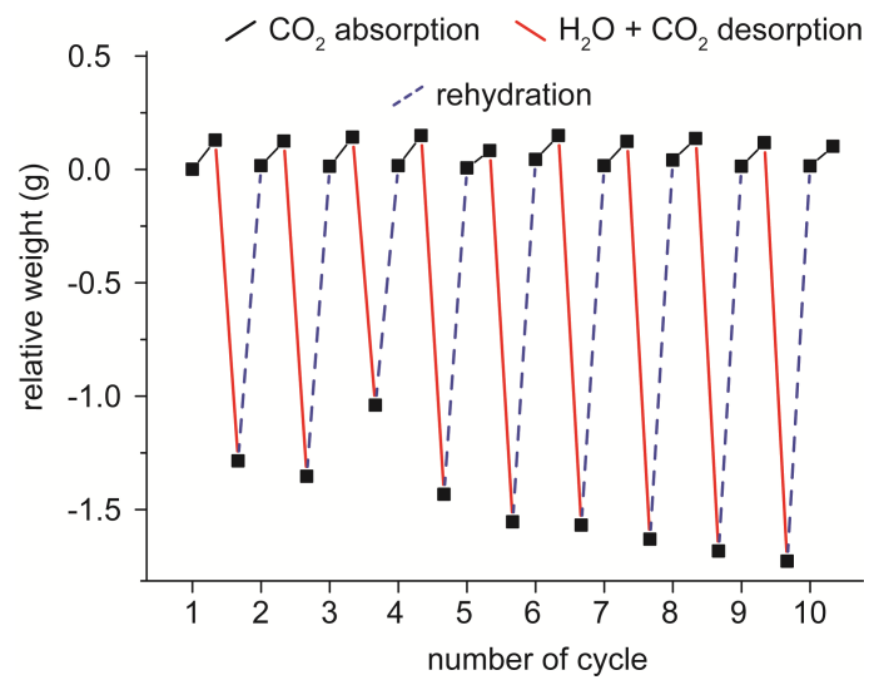

Figure 7. Recyclability of system B.

It can be noted that the amount of water lost in the desorption step slightly increases with the number of cycles. This is likely due to the evaporation of a small amount of EG during the desorption step, which is replaced with water in the re-hydration step. Anyway, in an optimized process, water and EG can be condensed again in the system at every cycle, reducing the necessity of an external refill. It is obvious that this system is intrinsically insensitive to flue gas humidity, which contrarily to many systems could be even beneficial, as it would maintain the hydration of the system without adding external water.

\section{$\mathrm{CO}_{2}$ absorption at high pressure.}

Absorption experiments have been carried out also at higher pressure of pure $\mathrm{CO}_{2}(10$ and 20 atm), obtaining a considerable increase of amount of absorbed gas.

In fact, the system $\mathbf{B}$ absorbs $80 \mathrm{~g}_{\mathrm{CO} 2} / \mathrm{kg}_{\text {sorbent }}$ at $40^{\circ} \mathrm{C}$ and 40 bar of $\mathrm{CO}_{2}$, but if the stirring is moderate, the process is really slow $(24 \mathrm{~h})$. Under a vigorous stirring, the same system absorbs the same amount of gas in 100 min, quickly reaching a plateau.

Using system $\mathbf{D}$, which ensure a lower viscosity and under a vigorous stirring, the absorption has been studied at different conditions of pressure (10 and $20 \mathrm{~atm}$ ) and temperature (from 25 to $55^{\circ} \mathrm{C}$ ). In all the cases, the maximum absorption is $83 \mathrm{~g}_{\mathrm{CO} 2} / \mathrm{kg}_{\text {sorbent }}$ (Figure 8) which corresponds to $58 \%$ mol $\mathrm{CO}_{2} / \mathrm{mol}_{\mathrm{KOH}}$ and appears to be the superior limit of absorbance for this system. The temperature does not play a major role in determining the absorbance, but it dictates the absorption kinetics, most likely through the control of viscosity. 

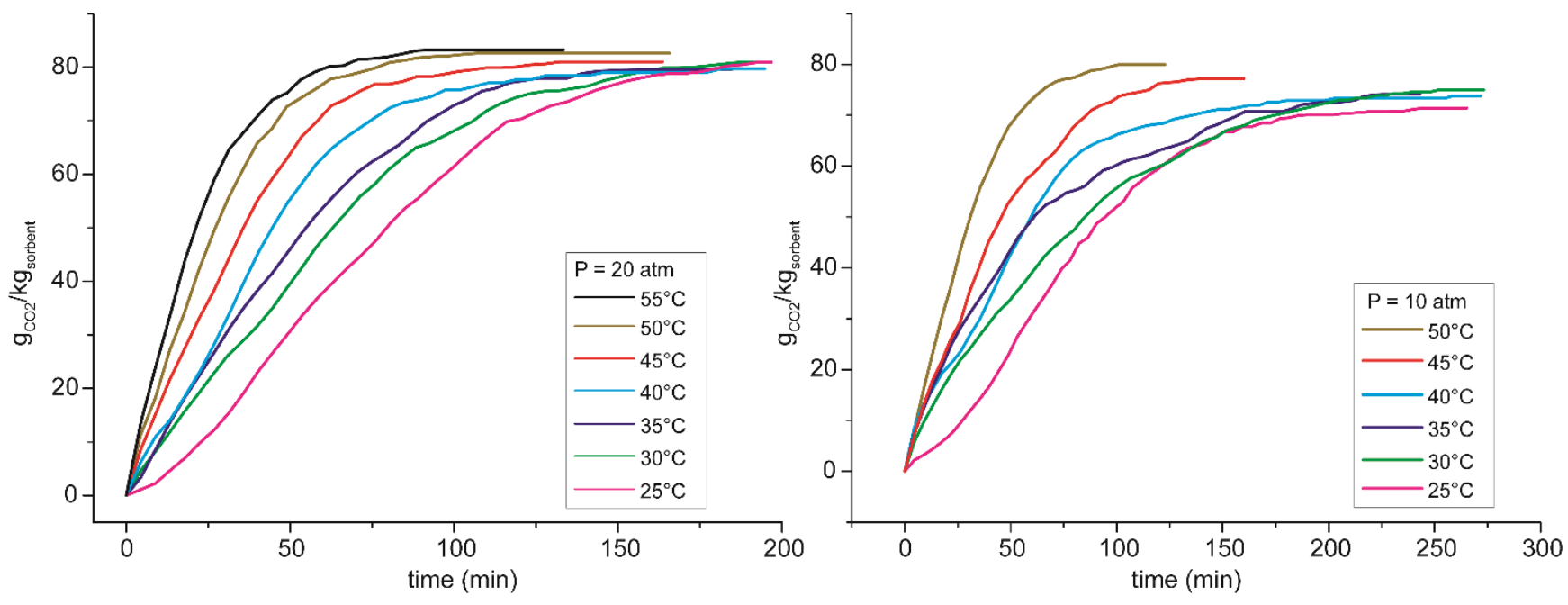

Figure 8. Kinetics of $\mathrm{CO}_{2}$ absorption at different temperature and pressure values.

The initial absorption rate is quite linear with time, with a slope going from 0.65 to $2.18 \mathrm{~g}_{\mathrm{CO} 2} /$ $\mathrm{kg}_{\text {sorbent }}{ }^{*} \mathrm{~min}$ at $20 \mathrm{bar}$, then it reaches a plateau. These initial slopes can be plotted according to the Eyring equation (Figure 9), obtaining the activation parameters for the absorption in this experimental setup. The Eyring plot is satisfactorily linear $\left(\mathrm{r}^{2}=0.966\right)$ and provides the following activation parameters: $\Delta \mathrm{H}^{\dagger}=7.6 \pm 0.3 \mathrm{kcal} / \mathrm{mol}$ and $\Delta \mathrm{S}^{\ddagger}=-34 \pm 2 \mathrm{eu}$. The large and negative activation entropy is consistent with the gas capture.

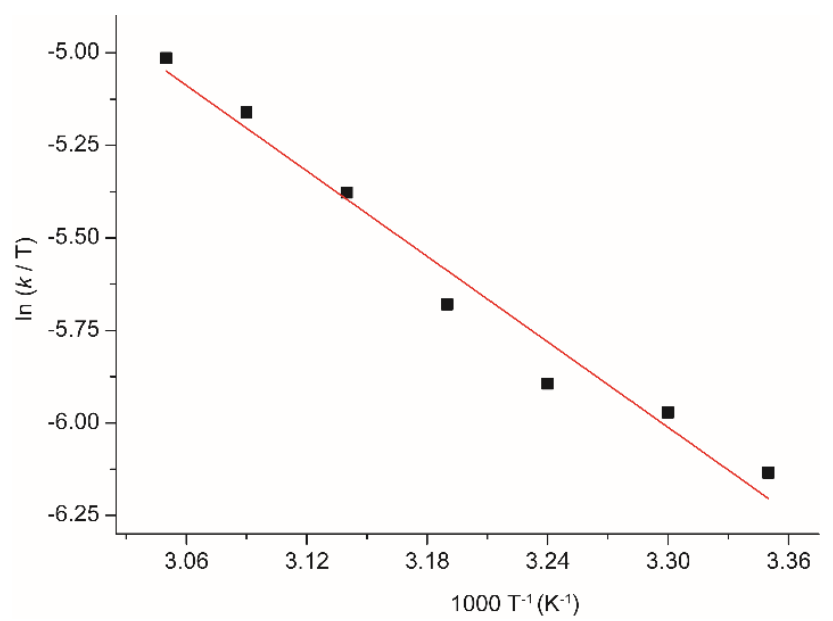

Figure 9. Eyring plot for the $\mathrm{CO}_{2}$ absorption of system $\mathbf{D}$ at $20 \mathrm{bar}\left(\mathrm{r}^{2}=0.966\right)$.

The same analysis with data at 10 bar leads to the following results: $\Delta H^{\ddagger}=10.6 \pm 0.6 \mathrm{kcal} / \mathrm{mol}$ and $\Delta \mathrm{S}^{\ddagger}$ $=-25 \pm 2$ eu (Supplementary Information). 
Finally, with the aim to better reproduce realistic conditions, a mixture $\mathrm{N}_{2} / \mathrm{CO}_{2}$ has been used, with a 85.2/14.8 ratio and at $\mathrm{P}_{\text {tot }}=1$ atm. At $\mathrm{T}=35^{\circ} \mathrm{C}$ (temperature at which the sorbent showed the best absorption rate at room pressure) and under a flux rate of $10 \mathrm{~N} \mathrm{~mL} / \mathrm{min}$ for $60 \mathrm{~min}$, system $\mathbf{D}$ absorbs $11.2 \mathrm{~g}_{\mathrm{CO} 2} / \mathrm{kg}_{\text {sorbent }}$.

it should be noted that already in laboratory-scale and buying only highly pure reagents, the cost of the sorbent is only $24 € / \mathrm{kg}$, but using technical grade materials (as seen, glycol or potassium hydroxide does not need to be dry) and buying in bulk, this price would not exceed one fourth of such price.

\section{CONCLUSIONS}

Establishing new effective $\mathrm{CO}_{2}$ sorbents that are inexpensive enough to be industrially employed, without any toxic by-product, and robust enough to be recycled many times with a small energy input[9] is crucial for a successful Carbon Capture strategy, at least as a temporary solution until the use of fossil fuels will be finally discarded. The quaternary system based on ethylene glycol, which can be considered renewable if produced from biomass, potassium hydroxide, boric acid and water $(3: 1: 1: 3)$, fulfils all these requirements, absorbing up to $59 \mathrm{~g}_{\mathrm{CO} 2} / \mathrm{kg}_{\text {sorbent }}$ at $28^{\circ} \mathrm{C}$ and $1 \mathrm{~atm}$ of pure $\mathrm{CO}_{2}$. The regeneration step is quantitative, fast and mild, as only $60^{\circ} \mathrm{C}$ under a gentle $\mathrm{N}_{2}$ flow (or reduced pressure) is required. No toxic by-products are formed under these conditions, differently than with aqueous amine methods, and the regeneration step is much less energy-requiring than standard hydroxide/carbonate methods thanks to the presence of boric acid. Under higher $\mathrm{CO}_{2}$ pressure, the absorption capacity increases up to 83 $\mathrm{g}_{\mathrm{CO} 2} / \mathrm{kg}_{\text {sorbent }}$ and the absorption kinetics increases beyond $2 \mathrm{~g}_{\mathrm{CO} 2} / \mathrm{kg}_{\text {sorbent }} * \mathrm{~min}$.

Finally, the system is chemically robust and can be recycled many times without any remarkable loss of performance, it is intrinsically insensitive to the presence of water in the $\mathrm{CO}_{2}$ stream, which is even beneficial for its capacity, and does not increase its viscosity upon carbonation. Further tests and optimization are currently in progress in our laboratory to verify the performance of this system under more realistic conditions.

\section{EXPERIMENTAL DETAILS}

All the reactants have been obtained from Merck and Alfa Aesar and were of the highest purity available. Ethylene glycol contained $1 \%$ of water, according to the Karl Fischer coulombometric titration. Boric acid has been recrystallized from hot water. Manipulation of EG/KOH mixtures was carried out under dry $\mathrm{N}_{2}$ using standard Schlenk techniques. NMR spectra were recorded at $25^{\circ} \mathrm{C}$ on a Bruker Avance II DRX400 instrument equipped with a BBFO broadband probe. All the liquid samples have been analysed 
without dilution in deuterated solvents, in order to avoid a perturbation on the chemical species or their relative abundance. For this, it has been used an external lock $\left(\mathrm{D}_{2} \mathrm{O}\right)$. Carbon and hydrogen analyses were performed with a Vario MICRO cube instrument (Elementar). No nitrogen and sulphur have been found in any sample.

Transition temperature determination. In a $10 \mathrm{~mL}$ round-bottomed flask, equipped with a thermometer, weighed amounts of the system under study were introduced. The latter was heated until became homogenous liquids, and then were gradually cooled first to room temperature then immersed an acetone/liquid nitrogen bath to determine the transition temperature of systems $\mathbf{A}$ and $\mathbf{B}$.

Viscosity measurements. The viscosity of the systems was measured using a Fungilab Expert L viscometer, fitted with a thermostatic jacket and a temperature probe. The viscometer jacket was connected to an external thermostated bath. The viscosity measurements were obtained using a spindle attachment. Readings were taken after 20-25 minutes of homogenization for each temperature.

Conductivity measurements. Conductivity measurements were performed on an Analytical Control conductometer (model 120) equipped with a platinum cell (cell constant $=1.05 \mathrm{~cm}^{-1}$ ). Sample temperature was maintained constant by a glass-jacked beaker connected to a thermostatic bath. To ensure correlation between the results, the same sample was used for conductivity and viscosity experiments. The readings were taken after 20-25 minutes of homogenization for each temperature selected.

Thermal Gravimetric Analysis. Thermograms of the mixtures were obtained with a Thermogravimetric analyser Q5000 V3. The samples were heated from $25^{\circ} \mathrm{C}$ to $240^{\circ} \mathrm{C}$ with IR lamps under a pure $\mathrm{N}_{2}$ flow $\left(10^{\circ} \mathrm{C} / \mathrm{min}\right)$.

$\mathrm{CO}_{2}$ absorption at high pressure and in model flue gas. Experiments were conducted in a pressureresistant (up to 60 bar) AISI 316L stainless-steel reactor with an internal volume of $12 \mathrm{~mL}$. The reactor was equipped with a cooling/heating Peltier units bath system, which allows temperature to range from 273 to $353 \mathrm{~K}$, and an external magnetic stirring device, which allows constant and effective stirring of the sample during gas loading. The gas flow was measured by a F131 M series thermal mass flow meter (Bronkhorst High-Tech B.V., The Netherlands) with a measuring range of 10-500 N mL/min and 
maximum operating pressure of 300 bar. Pressure control and temperature control were obtained through a 4-20 mA pressure transducer (Gems Sensors \& Controls, United Kingdom, measuring range of 0-100 bar), and a resistive temperature detectors (RTD) PT100 class 1/3 DIN by OMEGA Engineering, Inc. (USA), respectively. The whole system was finely regulated by a custom-built process Arduino microcontroller (arduino.cc).

Model flue gas was prepared by adding a proper volume of $\mathrm{CO}_{2}$ and $\mathrm{N}_{2}$ into a gas cylinder. The exact percentage of $\mathrm{CO}_{2}$ into the gas mixture have been determined by means of an assembled in-house IR detector based on the Premier series of IR gas sensors for $\mathrm{CO}_{2}$ (Dynament, UK) controlled by an Arduino microcontroller (arduino.cc). The sensors have a measuring range of $0-100 \%$ and an accuracy better than $1 \%$ of the full scale. The obtained percentage of $\mathrm{CO}_{2}$ was $14.8 \%$ and, consequently, the percentage of $\mathrm{N}_{2}$ was $85.2 \%$. The $\mathrm{CO}_{2}$ absorption experiments were performed at $\mathrm{P}_{\text {tot }}=1$ atm and $\mathrm{T}=35{ }^{\circ} \mathrm{C}$ (temperature at which the sorbent has shown the best absorption rate at room pressure) in a glass vial closed with a rubber septum provided of a needle for the inlet and one for the outlet of the flue gas. The flux of the gas was regulated by a F131 M series thermal mass flow meter (Bronkhorst High-Tech B.V., The Netherlands) with a measuring range of 5-500 N mL/min. The quantification of the $\mathrm{CO}_{2}$ absorbed was performed gravimetrically. In particular, $1.5 \mathrm{~g}$ of TTM was accurately weighed into the glass vial and the flue gas was flowed through the sample, kept under stirring, at the flow rate of $10 \mathrm{~N} \mathrm{~mL} / \mathrm{min}$ for 60 min. Results are the average of 4 different experiments.

Preparation of system A. $30 \mathrm{~g}(483 \mathrm{mmol})$ of ethylene glycol were added to $9.04 \mathrm{~g}(161 \mathrm{mmol}) \mathrm{of} \mathrm{KOH}$ in pellets (without crushing them to minimize the water absorbed on the surface) under nitrogen atmosphere. As the dissolution of $\mathrm{KOH}$ in $\mathrm{EG}$ is strongly exothermic, the flask containing the heterogeneous mixture was placed in a water bath to get rid of the excess heat and stirred until complete dissolution of the pellets (2-4 h, approximately). The mixture has been always stored in protective atmosphere. After evaporation of all the volatiles $\left(6 \mathrm{~h}, 100^{\circ} \mathrm{C}\right.$ under vacuum), a yellow solid remained and was analysed via elemental analysis. Elemental analysis (\%) calcd for $\mathrm{C}_{4} \mathrm{H}_{12} \mathrm{~K}_{2} \mathrm{O}_{5}$ $\left.\left(\mathrm{KOCH}_{2} \mathrm{CH}_{2} \mathrm{OH}\right)_{2} * \mathrm{H}_{2} \mathrm{O}\right): \mathrm{C} 22.00$, H 5.54; found: C 21.93, H 5.86. ${ }^{13} \mathrm{C}\left\{{ }^{1} \mathrm{H}\right\} \mathrm{NMR}$ (external lock): 63.56 ppm, s.

Preparation of system B. $9.96 \mathrm{~g}$ of boric acid $(161 \mathrm{mmol})$ were added to $39.1 \mathrm{~g}$ of a freshly prepared system A. The heterogeneous mixture was stirred at ambient temperature without need of protective atmosphere until complete dissolution ( $3 \mathrm{~h}$, approximately). After evaporation of all the volatiles ( $6 \mathrm{~h}$, 
$100^{\circ} \mathrm{C}$ under vacuum), a white solid remained and was analysed via elemental analysis. Elemental analysis (\%) calcd for $\mathrm{C}_{8} \mathrm{H}_{21} \mathrm{BK}_{2} \mathrm{O}_{9}\left[\mathrm{~KB}(\mathrm{OH})\left(\mathrm{OCH}_{2} \mathrm{CH}_{2} \mathrm{OH}\right)_{3} * \mathrm{KOCH}_{2} \mathrm{CH}_{2} \mathrm{OH}\right]$ : C 27.43, $\mathrm{H}$ 6.04; found: C 27.82, H 5.68. ${ }^{13} \mathrm{C}\left\{{ }^{1} \mathrm{H}\right\}$ NMR (external lock): 62.70 ppm, s. ${ }^{11}$ B NMR (external lock): 9.63 (br, s), 6.20 (br, s).

Preparation of system $\mathbf{C}$ and $\mathbf{D}$. The appropriate amount of water ( 2 and 3 equivalents with respect to the original amount of $\mathrm{KOH}$ for system $\mathbf{C}$ and $\mathbf{D}$, respectively) was added to system $\mathbf{B}$ and stirred for some minutes until complete homogenization.

$\mathrm{CO}_{2}$ absorption/desorption. $3.4 \mathrm{~g}$ of absorbent were placed in a $25 \mathrm{~mL}$ flask in a bath at the desired temperature, stirred at the maximum rate allowed by the viscosity of the system and contacted with a $\mathrm{CO}_{2}$ atmosphere for the desired time (generally, 30 minutes). The amount of absorbed gas (normally around $0.1 \mathrm{~g})$ was estimated gravimetrically with an analytical balance $( \pm 0.1 \mathrm{mg})$. For the $\mathrm{CO}_{2}$ desorption, the same sample used for carbonation was placed in a bath at $60^{\circ} \mathrm{C}$ and under a gentle nitrogen gas flow for 30 minutes. The release was confirmed by NMR spectroscopy, analysing the absence of peaks in the region between 155 and $170 \mathrm{ppm}$.

For high pressure absorption experiments, approximately $2 \mathrm{~g}$ of absorbent were weighed directly in the reactor and allowed to equilibrate to the desired temperature, in the range 298-328 K. At first, $\mathrm{CO}_{2}$ was flowed under vacuum through the apparatus, in order to remove air and moisture. The system was then loaded with the gas up to the desired pressure (10 and 20 bar). The sample was continuously stirred during gas loading, and the amount of absorbed $\mathrm{CO}_{2}$ was recorded by the flow meter as a function of time until a plateau was reached, corresponding to the maximum amount of loaded $\mathrm{CO}_{2}$.

\section{SUPPLEMENTARY INFORMATION AVAILABLE}

NMR spectra and thermograms of systems before and after carbonation, additional tables.

\section{CONFLICT OF INTEREST.}

The authors declare no conflict of interest.

\section{ACKNOWLEDGEMENTS}

GC thanks University of Pisa for financial support (Fondi di Ateneo 2020). Dr. Marco Taddei, Edoardo Buttarazzi and Dr. Giulio Bresciani are acknowledged for helpful discussions and technical support. 


\section{AUTHOR CONTRIBUTION}

Marcello Costamagna, Eleonora Micheli, Valentino Canale, Michele Ciulla: investigation and data curation; Gabriella Siani, Pietro di Profio: supervision, writing; Matteo Tiecco, Gianluca Ciancaleoni: conceptualization, formal analysis, supervision, writing.

\section{BIBLIOGRAPHY}

[1] Communication from the Commission to the European economic and social Committee and the Committee of the Regions. A hydrogen strategy for a climate-neutral Europe, (2020). https://op.europa.eu/s/ovyl.

[2] M. David, C. Ocampo-Martínez, R. Sánchez-Peña, Advances in alkaline water electrolyzers: A review, J. Energy Storage. 23 (2019) 392-403. https://doi.org/10.1016/j.est.2019.03.001.

[3] S. Shiva Kumar, V. Himabindu, Hydrogen production by PEM water electrolysis - A review, Mater. Sci. Energy Technol. 2 (2019) 442-454. https://doi.org/10.1016/j.mset.2019.03.002.

[4] P. Gabrielli, M. Gazzani, M. Mazzotti, The Role of Carbon Capture and Utilization, Carbon Capture and Storage, and Biomass to Enable a Net-Zero-CO2 Emissions Chemical Industry, Ind. Eng. Chem. Res. 59 (2020) 7033-7045. https://doi.org/10.1021/acs.iecr.9b06579.

[5] D.M. Reiner, Learning through a portfolio of carbon capture and storage demonstration projects, Nat. Energy. 1 (2016) 1-7. https://doi.org/10.1038/nenergy.2015.11.

[6] R.M. Cuéllar-Franca, A. Azapagic, Carbon capture, storage and utilisation technologies: A critical analysis and comparison of their life cycle environmental impacts, J. CO2 Util. 9 (2015) 82-102. https://doi.org/10.1016/j.jcou.2014.12.001.

[7] B.S. Koelbl, M.A. van den Broek, A.P.C. Faaij, D.P. van Vuuren, Uncertainty in Carbon Capture and Storage (CCS) deployment projections: A cross-model comparison exercise, Clim. Change. 123 (2014) 461-476. https://doi.org/10.1007/s10584-013-1050-7.

[8] J. Sekera, A. Lichtenberger, Assessing Carbon Capture: Public Policy, Science, and Societal Need, Biophys. Econ. Sustain. 5 (2020) 14. https://doi.org/10.1007/s41247-020-00080-5.

[9] H.A. Patel, J. Byun, C.T. Yavuz, Carbon Dioxide Capture Adsorbents: Chemistry and Methods, ChemSusChem. 10 (2017) 1303-1317. https://doi.org/10.1002/cssc.201601545.

[10] P. Luis, Use of monoethanolamine (MEA) for CO2 capture in a global scenario: Consequences and alternatives, Desalination. 380 (2016) 93-99. https://doi.org/10.1016/j.desal.2015.08.004.

[11] C.J. Nielsen, H. Herrmann, C. Weller, Atmospheric chemistry and environmental impact of the 
use of amines in carbon capture and storage (CCS), Chem. Soc. Rev. 41 (2012) 6684-6704. https://doi.org/10.1039/c2cs35059a.

[12] A.E. Poste, M. Grung, R.F. Wright, Amines and amine-related compounds in surface waters: A review of sources, concentrations and aquatic toxicity, Sci. Total Environ. 481 (2014) 274-279. https://doi.org/10.1016/j.scitotenv.2014.02.066.

[13] F. Barzagli, S. Lai, F. Mani, Novel non-aqueous amine solvents for reversible CO2 capture, in: Energy Procedia, Elsevier Ltd, 2014: pp. 1795-1804. https://doi.org/10.1016/j.egypro.2014.11.186.

[14] F. Barzagli, F. Mani, M. Peruzzini, Novel water-free biphasic absorbents for efficient CO2 capture, Int. J. Greenh. Gas Control. 60 (2017) 100-109. https://doi.org/10.1016/j.ijggc.2017.03.010.

[15] Q. Ye, X. Wang, Y. Lu, Screening and evaluation of novel biphasic solvents for energy-efficient post-combustion CO2 capture, Int. J. Greenh. Gas Control. 39 (2015) 205-214. https://doi.org/10.1016/j.ijggc.2015.05.025.

[16] K.S. Lackner, H. Ziock, P. Grimes, Carbon Dioxide Extraction from Air: Is It an Option?, in: Proc. 24th Annu. Tech. Conf. Coal Util. Fuel Syst., Clearwater, FL, 1999: pp. 885-896.

[17] E.S. Sanz-Pérez, C.R. Murdock, S.A. Didas, C.W. Jones, Direct Capture of CO2 from Ambient Air, Chem. Rev. 116 (2016) 11840-11876. https://doi.org/10.1021/acs.chemrev.6b00173.

[18] D.J. Heldebrant, P.K. Koech, V.A. Glezakou, R. Rousseau, D. Malhotra, D.C. Cantu, WaterLean Solvents for Post-Combustion CO2 Capture: Fundamentals, Uncertainties, Opportunities, and Outlook, Chem. Rev. 117 (2017) 9594-9624. https://doi.org/10.1021/acs.chemrev.6b00768.

[19] M. Ding, R.W. Flaig, H.L. Jiang, O.M. Yaghi, Carbon capture and conversion using metalorganic frameworks and MOF-based materials, Chem. Soc. Rev. 48 (2019) 2783-2828. https://doi.org/10.1039/c8cs00829a.

[20] J.M. Taylor, R.K. Mah, G.K.H. Shimizu, Synthesis of zinc MOFs material, WO 2019204934, 2013.

[21] G. Siani, M. Tiecco, P. Di Profio, S. Guernelli, A. Fontana, M. Ciulla, V. Canale, Physical absorption of CO2 in betaine/carboxylic acid-based Natural Deep Eutectic Solvents, J. Mol. Liq. 315 (2020) 113708. https://doi.org/10.1016/j.molliq.2020.113708.

[22] S. Sarmad, J.P. Mikkola, X. Ji, Carbon Dioxide Capture with Ionic Liquids and Deep Eutectic Solvents: A New Generation of Sorbents, ChemSusChem. 10 (2017) 324-352. https://doi.org/10.1002/cssc.201600987. 
[23] X. Luo, Y. Guo, F. Ding, H. Zhao, G. Cui, H. Li, C. Wang, Significant improvements in CO2 capture by pyridine-containing anion-functionalized ionic liquids through multiple-site cooperative interactions, Angew. Chemie - Int. Ed. 53 (2014) 7053-7057. https://doi.org/10.1002/anie.201400957.

[24] O. Aschenbrenner, P. Styring, Comparative study of solvent properties for carbon dioxide absorption, Energy Environ. Sci. 3 (2010) 1106-1113. https://doi.org/10.1039/c002915g.

[25] M.R. Mahi, I. Mokbel, L. Negadi, F. Dergal, J. Jose, Experimental solubility of carbon dioxide in monoethanolamine, or diethanolamine or N-methyldiethanolamine (30 wt \%) dissolved in deep eutectic solvent (choline chloride and ethylene glycol solution), J. Mol. Liq. 289 (2019) 111062. https://doi.org/10.1016/j.molliq.2019.111062.

[26] H. Yue, Y. Zhao, X. Ma, J. Gong, Ethylene glycol: Properties, synthesis, and applications, Chem. Soc. Rev. 41 (2012) 4218-4244. https://doi.org/10.1039/c2cs15359a.

[27] Y. Zhang, A. Wang, T. Zhang, A new 3D mesoporous carbon replicated from commercial silica as a catalyst support for direct conversion of cellulose into ethylene glycol, Chem. Commun. 46 (2010) 862-864. https://doi.org/10.1039/b919182h.

[28] SUBSTITUTION OF SOLVENTS BY SAFER PRODUCTS, in: Handb. Solvents, Elsevier, 2019: pp. 1455-1634. https://doi.org/10.1016/b978-1-927885-41-3.50010-3.

[29] L. Brinchi, R. Germani, E. Braccalenti, N. Spreti, M. Tiecco, G. Savelli, Accelerated decarboxylation of 6-nitrobenzisoxazole-3-carboxylate in imidazolium-based ionic liquids and surfactant ionic liquids, J. Colloid Interface Sci. 348 (2010) 137-145. https://doi.org/10.1016/j.jcis.2010.04.029.

[30] A. Messaâdi, N. Dhouibi, H. Hamda, F.B.M. Belgacem, Y.H. Adbelkader, N. Ouerfelli, A.H. Hamzaoui, A New Equation Relating the Viscosity Arrhenius Temperature and the Activation Energy for Some Newtonian Classical Solvents, J. Chem. 2015 (2015). https://doi.org/10.1155/2015/163262.

[31] K. Hickey, W. Earle Waghorne, A. Sacco, Comparison of the activation free energies for viscous flow and for diffusion in dilute solutions, derivation of the expression for the effect of the solute on the activation free energy of diffusion of the solvent, and application to solutions of N,N-dim, J. Phys. Chem. A. 105 (2001) 1093-1096. https://doi.org/10.1021/jp003027d.

[32] F. Cardellini, M. Tiecco, R. Germani, G. Cardinali, L. Corte, L. Roscini, N. Spreti, Novel zwitterionic deep eutectic solvents from trimethylglycine and carboxylic acids: Characterization of their properties and their toxicity, RSC Adv. 4 (2014) 55990-56002. 
https://doi.org/10.1039/c4ra10628h.

[33] D.R. MacFarlane, M. Forsyth, E.I. Izgorodina, A.P. Abbott, G. Annat, K. Fraser, On the concept of ionicity in ionic liquids, Phys. Chem. Chem. Phys. 11 (2009) 4962-4967. https://doi.org/10.1039/b900201d.

[34] D. Rengstl, V. Fischer, W. Kunz, Low-melting mixtures based on choline ionic liquids, Phys. Chem. Chem. Phys. 16 (2014) 22815-22822. https://doi.org/10.1039/c4cp02860k.

[35] Y. Wang, W. Chen, Q. Zhao, G. Jin, Z. Xue, Y. Wang, T. Mu, Ionicity of deep eutectic solvents by Walden plot and pulsed field gradient nuclear magnetic resonance (PFG-NMR), Phys. Chem. Chem. Phys. 22 (2020) 25760-25768. https://doi.org/10.1039/d0cp01431a.

[36] K.R. Harris, On the Use of the Angell-Walden Equation to Determine the "Ionicity" of Molten Salts and Ionic Liquids, J. Phys. Chem. B. 123 (2019) 7014-7023. https://doi.org/10.1021/acs.jpcb.9b04443.

[37] H. Ghaedi, M. Ayoub, S. Sufian, A.M. Shariff, B. Lal, C.D. Wilfred, Density and refractive index measurements of transition-temperature mixture (deep eutectic analogues) based on potassium carbonate with dual hydrogen bond donors for $\mathrm{CO} 2$ capture, J. Chem. Thermodyn. 118 (2018) 147-158. https://doi.org/10.1016/j.jct.2017.11.008.

[38] G. Cui, M. Lv, D. Yang, Efficient CO2 absorption by azolide-based deep eutectic solvents, Chem. Commun. 55 (2019) 1426-1429. https://doi.org/10.1039/c8cc10085c.

[39] R. Li, C. Wu, D. Yang, CO2 Absorption Mechanism by the Nonaqueous Solvent Consisting of Hindered Amine 2-[(1,1-dimethylethyl)amino]ethanol and Ethylene Glycol, Molecules. 25 (2020) 5743. https://doi.org/10.3390/molecules25235743.

[40] M. Rahimi, G. Catalini, M. Puccini, T.A. Hatton, Bench-scale demonstration of CO2capture with an electrochemically driven proton concentration process, RSC Adv. 10 (2020) 1683216843. https://doi.org/10.1039/d0ra02450c.

[41] D. Uysal, Ö.M. Dogan, B.Z. Uysal, Kinetics of Absorption of Carbon Dioxide into Sodium Metaborate Solution, Int. J. Chem. Kinet. 49 (2017) 377-386. https://doi.org/10.1002/kin.21082.

[42] D. Guo, H. Thee, G. Da Silva, J. Chen, W. Fei, S. Kentish, G.W. Stevens, Borate-catalyzed carbon dioxide hydration via the carbonic anhydrase mechanism, Environ. Sci. Technol. 45 (2011) 4802-4807. https://doi.org/10.1021/es200590m.

[43] A. Filippov, O.N. Antzutkin, F.U. Shah, Understanding the Interaction of Boric Acid and CO2 with Ionic Liquids in Aqueous Medium by Multinuclear NMR Spectroscopy, ACS Sustain. Chem. Eng. 8 (2020) 552-560. https://doi.org/10.1021/acssuschemeng.9b06068. 
[44] Y. Matsuzaki, S. Yamamoto, H. Yamada, F.A. Chowdhury, K. Goto, Catalysis of CO2Absorption in an Aqueous Alkanolamine Solution by Boron Compounds: A Combined Computational and Experimental Study, Ind. Eng. Chem. Res. 59 (2020) 13016-13023. https://doi.org/10.1021/acs.iecr.0c02756.

[45] L. Lombardo, H. Yang, K. Zhao, P.J. Dyson, A. Züttel, Solvent- and Catalyst-Free Carbon Dioxide Capture and Reduction to Formate with Borohydride Ionic Liquid, ChemSusChem. 13 (2020) 2025-2031. https://doi.org/10.1002/cssc.201903514.

[46] L.M.S.G.A. Applegarth, C.C. Pye, J.S. Cox, P.R. Tremaine, Raman Spectroscopic and ab Initio Investigation of Aqueous Boric Acid, Borate, and Polyborate Speciation from 25 to $80^{\circ} \mathrm{c}$, Ind. Eng. Chem. Res. 56 (2017) 13983-13996. https://doi.org/10.1021/acs.iecr.7b03316. 
Graphical Abstract

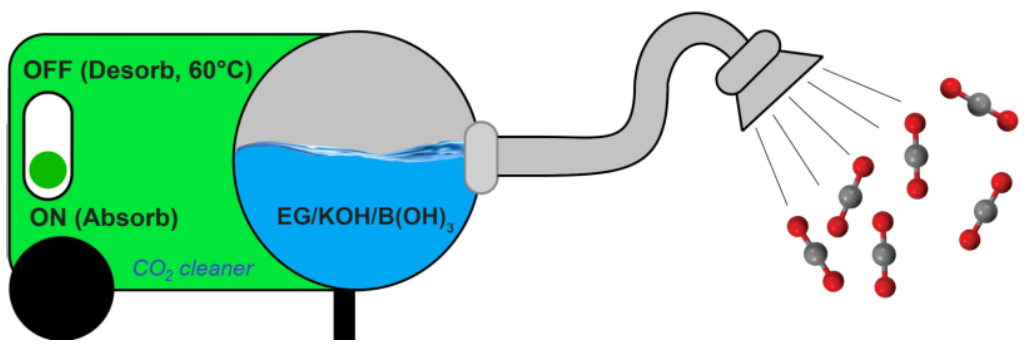

